\title{
Psychological response to growth hormone treatment in short normal children
}

\author{
A Bruce Downie, Jean Mulligan, Elizabeth S McCaughey, Robert J Stratford, \\ Peter R Betts, Linda D Voss
}

\begin{abstract}
This study provides a controlled assessment of the psychological (and physical) effects of growth hormone treatment. Fifteen short 'normal' children (height SD score $<-2$ ) have been treated with growth hormone since the age of $7 / 8$ years. They, together with untreated short controls and average controls (10th-90th centiles), were assessed at recruitment, after three years, and after five years. Only the treated group showed a significant height increase (SD score -2.44 to -1.21 over five years). No significant differences were found at recruitment, three years, or five years in IQ, attainment, behaviour, or self esteem. Also at five years, there were no significant differences in locus of control, self perception, or parental perceptions of competence. Both short groups displayed less satisfaction with their height than the controls $(p<0.01)$, though all groups were optimistic of being tall adults. The treated children were no more unrealistic over final height than the untreated children. To date, no psychological benefits of treatment have been demonstrated; but nor have there been any discernible ill effects for either the treated or the untreated children.

(Arch Dis Child 1996;75:32-35)
\end{abstract}

Department of Child Health, Southampton University Hospitals Trust, Mail Point 803,

Southampton General

Hospital,

Southampton

SO16 6YD

AB Downie

$\mathrm{J}$ Mulligan

E McCaughey

LD Voss

Department of

Psychology,

Southampton

University

RJ Stratford

Department of

Paediatrics,

Southampton

University Hospitals

Trust

PR Betts

Correspondence to:

Dr Downie.

Accepted 19 February 1996
Keywords: growth hormone, short stature, psychometric testing.

The literature predominantly supports the view that short stature constitutes a psychosocial liability. ${ }^{12}$ Consequently, ethical discussions of the use of growth hormone treatment generally begin with the assumption that 'extreme' short stature must be a handicap. ${ }^{34}$ However, studies of short stature often extrapolate results from particular diagnostic groupings to all short children and most have contained serious methodological flaws, notably the lack of controls and the use of referred samples only. In addition, recent articles have indicated that short people may display normal psychosocial functioning. ${ }^{5-7}$

Though growth hormone treatment increases the growth of many short children, there are reservations over whether the short term gains in growth velocity will result in improved final adult height. ${ }^{8-10}$ It has been argued that such short term growth may none the less be psychologically beneficial for the short child.

Previous trials found that treatment had no significant effect on cognitive function, as reflected in IQ levels. 61112 Studies have reported both an improvement in behaviour after treatment ${ }^{6}$ as well as deterioration. ${ }^{11} 1314$ It has been suggested that treated children may be subject to a 'syndrome of readjustment' to their altered appearance. ${ }^{15}$ However, self concept has been found to be within the normal range after treatment. ${ }^{6} 16$

With one exception, ${ }^{16}$ the studies examined above reported either negative effects ${ }^{13} 14$ or no clear effect after growth hormone treatment. Only two studies used a sample of short normal children ${ }^{6}{ }^{16}$ - the rest used growth hormone deficient children. They all involved referred samples and none used average stature controls.

The present investigation responds to the clear need for a controlled study. Evaluation of the psychological effects of growth hormone treatment was made by comparison with a group of untreated short normal children and a group of children of average stature. The children were all 'normal' and were recruited from the community, not through clinic referral. They were approximately the same age, began treatment at a similar age, and received growth hormone for the same length of time.

\section{Subjects and methods}

\section{SUBJECTS}

The subjects were recruited from the Wessex Growth Study, ${ }^{5}$ which compares 140 short normal children with 140 controls of average stature.

The present trial was begun in 1989. Ninety of the short children were then 2 height SD scores or more below the mean, and 41 agreed to participate in the trial. Twenty one were randomly allocated to the treatment group and 20 to the untreated group. A control group of 21 children of average stature originally case matched to the treated children was also assessed.

At the time of the present assessment, five years into the trial (1994/5), there were 13 untreated children (seven boys, six girls), and 15 each in the treated and control groups (seven boys, eight girls). ${ }^{10}$ 
Table 1 Full results table. Mean total scores and pooled SDs from one way analysis of variance for all measures

\begin{tabular}{|c|c|c|c|c|c|}
\hline $\begin{array}{l}\text { Assessment and year } \\
\text { of measurement }\end{array}$ & Untreated $(n=13)$ & Treated $(n=15)$ & Controls $(n=15)$ & Pooled SD & p Value \\
\hline \multicolumn{6}{|c|}{ Intelligence (BAS) (mean IQ score) } \\
\hline 0 & 104.8 & 103.0 & 103.8 & 13.74 & 0.944 \\
\hline 3 & 104.1 & 102.1 & 106.9 & 16.27 & 0.734 \\
\hline 5 & 108.8 & 104.9 & 113.6 & 14.26 & 0.256 \\
\hline \multicolumn{6}{|c|}{ Attainment: word reading (BAS) (mean T score) } \\
\hline 0 & 45.8 & 45.2 & 46.1 & 10.48 & 0.969 \\
\hline 3 & 47.7 & 45.9 & 48.5 & 8.59 & 0.726 \\
\hline 5 & 46.6 & 43.6 & 46.9 & 8.06 & 0.471 \\
\hline \multicolumn{6}{|c|}{ Attainment: basic number skills (BAS) (mean T score) } \\
\hline 0 & 46.8 & 42.8 & 43.1 & 7.23 & 0.275 \\
\hline 3 & 41.9 & 37.8 & 39.5 & 8.47 & 0.445 \\
\hline 5 & 42.6 & 40.1 & 42.6 & 8.46 & 0.647 \\
\hline \multicolumn{6}{|c|}{ Behaviour (teacher's Rutter) } \\
\hline 0 & 4.82 & 4.71 & 5.31 & 4.26 & 0.930 \\
\hline 3 & 6.82 & 6.71 & 7.77 & 7.50 & 0.925 \\
\hline 5 & 4.27 & 5.86 & 7.20 & 6.73 & 0.637 \\
\hline \multicolumn{6}{|c|}{ Behaviour (parent's Rutter) } \\
\hline 0 & 11.46 & 11.36 & 13.17 & 7.05 & 0.773 \\
\hline 3 & 10.00 & 8.60 & 11.08 & 7.12 & 0.665 \\
\hline 5 & 8.31 & 8.40 & 9.80 & 6.10 & 0.762 \\
\hline \multicolumn{6}{|l|}{ Self esteem (Battle) } \\
\hline 0 & 19.8 & 18.7 & 18.4 & 3.60 & 0.638 \\
\hline 3 & 18.5 & 19.7 & 17.9 & 4.10 & 0.516 \\
\hline 5 & 19.5 & 20.6 & 20.5 & 3.98 & 0.751 \\
\hline \multicolumn{6}{|c|}{ Self perception (Harter) } \\
\hline 5 & 105.2 & 105.5 & 104.2 & 17.44 & 0.979 \\
\hline \multicolumn{6}{|c|}{ Parent's perception (Harter) } \\
\hline 5 & 48.2 & 47.7 & 48.5 & 6.99 & 0.949 \\
\hline \multicolumn{6}{|c|}{ Locus of control (Nowicki-Strickland) } \\
\hline 5 & 15.23 & 15.27 & 13.27 & 5.52 & 0.537 \\
\hline
\end{tabular}

METHODS

The treated children received $30 \mathrm{IU} / \mathrm{m}^{2} /$ week of recombinant human growth hormone (Genotropin, Pharmacia UK). Psychometric assessment was made at recruitment, at three years, and at five years.

All three assessments used measures of intelligence (the British ability scales (BAS) short form IQ test ${ }^{17}$ ), attainment (BAS word reading and basic number skills ${ }^{17}$ ), behaviour (Rutter's Children's Behaviour Questionnaires ${ }^{18}$ ), and self esteem (Culture Free Self Esteem Inventory $\left.{ }^{19}\right)$. In year 5 , measures were added of locus of control (Nowicki and Strickland ${ }^{20}$ ), body image (Body Satisfaction Index, derived from Dowdney et $a l^{21}$ ), the children's self perception and their parents'perception (both Harter ${ }^{22}$ ).

At year 5, the two groups of short children were compared on all measures with the rest of the short children $(n=87)$ in the larger study sample ${ }^{5}$ (including those 42 short children originally eligible who did not participate in the trial). The controls were compared with the rest of the average stature children $(n=104)$.

\section{Results}

There was a significant increase in the mean height SD score for the treated group only $(p<0.001)$. The mean height SD score of the treated children was -2.44 at year $0,-1.17$ at year 3 , and -1.21 at year 5 . This represents a mean increase of some $8 \mathrm{~cm}$. Equivalent height SD score measures for the untreated group were $-2.47,-2.40$, and -2.35 ; and for the control group $+0.20,+0.17$, and +0.33 .

As shown in table 1 , there were no significant differences, whenever tested, on the measures of intelligence, attainment, behaviour as reported by teachers or parents, or self esteem. On both Rutter questionnaires, there were no significant differences at any time in the numbers of children with a total score denoting likely behavioural disorder. ${ }^{18}$ The correlation between the parents' and the teachers' ratings was 0.433 in year $5(p<0.005)$.

In year 5 , there were no significant differences on the Harter measures of the children's self perception or the parents' perception. The correlation between the parents' and the children's perceptions was $0.554(p<0.0001)$. There were likewise no significant differences on the measure of locus of control. However, on the measure of body image, treated and untreated short children did not differ significantly from each other on any part of the measure (table 2). Both treated and untreated children differed from the controls in perceived present height (both $\mathrm{p}<0.005$ ), but not in preferred present height or expected adult height. Using the comparison between present perceived and preferred height and weight to indicate the child's degree of body satisfaction (table 3), short children displayed significantly less satisfaction with their height than did controls $(p<0.01$ for treated; $p<0.005$ for untreated). There was no similar dissatisfaction with weight.

\section{COMPARISON AT YEAR 5 WITH THE REMAINDER} OF THE WESSEX GROWTH STUDY SAMPLE Only one important difference was found. On the Body Satisfaction Index, the treated children's present perceived height was significantly higher than that estimated by the rest of the short children $\left(\chi^{2}=8.26 ; p=0.04\right)$. However, the treated children were by then generally taller. This comparison suggests that the children in the trial were not atypical.

\section{Discussion}

Although the treated children are on average some $8 \mathrm{~cm}$ taller than the untreated ones, we have found no evidence up to early puberty that the psychosocial status of short normal 
Table 2 Group perceptions of present and future height; results are number of children

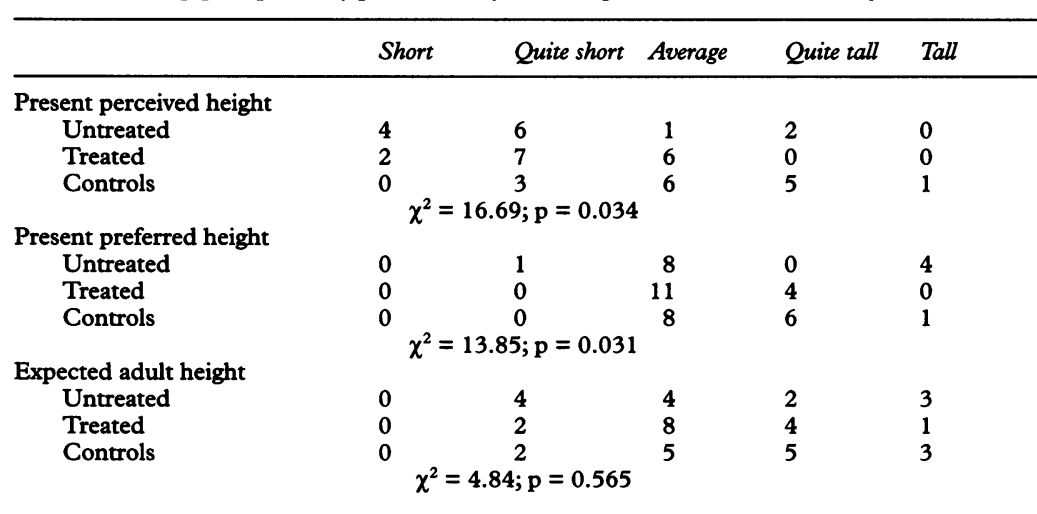

children is improved by growth hormone treatment. But neither is there any evidence of difficulties associated with new body size and shape, the 'readjustment syndrome', ${ }^{15}$ or with any perceived treatment failure. ${ }^{14}$

There are no indications at any time of testing that growth hormone treatment has affected intellectual development or attainment. While the IQs for all groups over the three assessments were above the BAS norms, attainment levels were consistently lower. ${ }^{17}$ This is probably due to changes in the schools' curriculum since 1976 when the tests were standardised.

In contrast to studies that have found that growth hormone treatment has had an effect on behaviour, ${ }^{61314}$ the parity of the behavioural ratings made by teachers and parents across the three groups remained stable over the duration of the study. The parents in all three groups recorded lower (that is, better) mean scores as time went on. The correlations between parents' and teachers' ratings suggest that there was agreement over individual children. There were also no significant differences across the groups in either the children's or the parents' perceptions on the behavioural subscale of the Harter measure, ${ }^{22}$ and good correlation between parents' and children's scores.

The self esteem of both groups of short children was similar on two measures to that of their taller peers, ${ }^{19} 22$ including self esteem derived from academic ability, which accords with the IQ and attainment findings above and elsewhere. ${ }^{6}$ The two groups of short children also showed as much self esteem as controls in the physical appearance and athletic domains, which conflicts with accounts that the physical aspects of short stature may be distressing. ${ }^{23}$ Parents' perceptions of their children's competence were similar across the three groups and correlated with the children's scores, suggest- ing the children were not exaggerating their reported self esteem.

The only measure to differentiate the short children from the controls was the Body Satisfaction Index. But even this did not distinguish the treated from the untreated group-they had similar degrees of dissatisfaction with their height (table 3 ). If the treated children did have exaggerated perceptions of their present height and unrealistic expectations of final adult height (table 2), they were demonstrably no more unrealistic than the untreated children in this study. As the treated children had become taller than the untreated group, they were arguably the more realistic in their expectations. Similarly, their estimation of greater present height compared with the rest of the short children in the larger study was also quite accurate. However, it was clear that most of the adolescent children in the trial would prefer to be 'average' or 'quite tall' (table 2). Even if short children are truly dissatisfied with their height, this trial shows that this is not necessarily accompanied by psychological morbidity.

Overall the results suggest that growth hormone treatment for a community sample of short normal children in early adolescence neither impairs nor improves psychosocial functioning. This highlights the dangers of extrapolating results from referred samples, where psychological difficulties may be present before the study has begun. ${ }^{7}$ The use of two control groups has demonstrated the imprudence of assessing treated (or short) individuals only. The results presented here for behaviour, attainment, and body satisfaction could have been wrongly interpreted without the benefit of comparison groups.

These results contribute to the current debate over the use of growth hormone treatment. Together with recent studies of community ${ }^{5}$ and clinic samples, ${ }^{7}$ they challenge the received wisdom concerning the 'handicap' of short stature. The question of treatment is perhaps more equivocal where short stature is the result of pathology, but even then there are few examples in the literature that demonstrate positive psychological adjustment resulting from growth hormone treatment. Counselling, as an alternative treatment for short children presenting with psychosocial difficulties, has several advocates. ${ }^{291114}$ It has been argued that growth hormone treatment itself may be psychologically detrimental. ${ }^{368}$ However, in common with the present trial, there are very few studies that show adverse effects arising from growth hormone treatment.

The findings presented here do not extend beyond early puberty. The benefits of in-

Table 3 Preferred height and weight compared with perceived height and weight; results are number of children

\begin{tabular}{|c|c|c|c|c|c|c|c|}
\hline & \multicolumn{3}{|c|}{ Height satisfaction } & & \multicolumn{3}{|c|}{ Weight satisfaction } \\
\hline & Untreated & Treated & Controls & & Untreated & Treated & Controls \\
\hline A lot taller & 4 & 3 & 1 & A lot plumper & 0 & 1 & 0 \\
\hline A bit taller & 8 & 9 & 3 & A bit plumper & 3 & 5 & 1 \\
\hline Happy & 1 & 3 & 10 & Happy & 7 & 6 & 9 \\
\hline A bit shorter & 0 & 0 & 1 & A bit thinner & 2 & 1 & 5 \\
\hline \multirow[t]{2}{*}{ A lot shorter } & 0 & 0 & 0 & A lot thinner & 1 & 2 & 0 \\
\hline & \multicolumn{3}{|c|}{$\chi^{2}=16.11 ; p=0.013$} & & \multicolumn{3}{|c|}{$\chi^{2}=9.96 ; p=0.268$} \\
\hline
\end{tabular}


creased stature may not yet be apparent and further assessments need to be made.

This study was generously supported by a research grant from the Wessex Regional Health Authority Research and Development Fund, and by a grant to the Wessex Medical School Trust from Pharmacia UK.

1 Underwood LE. The social cost of being short: societal perceptions and biases. Acta Paediatr Scand 1991; 377: 3-8.

2 Stabler B, Siegal PT, Clopper RR. Growth hormone deficiency in children has psychological and educational deficiency in children has psychological and educa

3 Diekema DS. Is taller really better? Growth hormone therapy in short children. Perspect Biol Med 1990; 34: 109-

4 Churchill LR. Bias, opportunity, and justice in growth hormone therapy. In: Stabler B, Underwood LE, eds. Growth stature, and adaptation. Chapel Hill: University of North Carolina, 1994:195-202.

5 Voss LD, Mulligan J. The short normal child in school: selfesteem, behaviour, and attainment before puberty (the Wessex Growth Study). In: Stabler B, Underwood LE, eds. Growth, stature, and adaptation. Chapel Hill: University of North Carolina, 1994:47-64.

6 Scarth LG, Gardiner HM. By taking thought: psychological studies of treated short normal children. In: Stabler B, Underwood LE, eds. Growth, stature, and adaptation. Chapel Hill: University of North Carolina, 1994:107-121.

7 Sandberg DE, Brook AE, Campos SP. Short stature: a psychosocial burden requiring growth hormone therapy? chosocial burden requiring

8 Grumbach MM. Growth hormone therapy and the short end of the stick. N Engl F Med 1988; 319: 238-40.

9 Stirling HF, Kelnar CJH. Who needs growth hormone? $f R$ Soc Med 1994; 87: 497-8.

10 McCaughey ES, Mulligan J, Voss LD, Betts PR. Growth and metabolic consequences of growth hormone treatment in prepubertal short normal children. Arch Dis Child 1994; 71: 201-6.
11 Frisch H, Hausler G, Lindenbauer S, Singer S. Psychological aspects in children and adolescents with hypopituitarism. Acta Paediatr Scand 1990; 79: 644-51.

12 Meyer-Bahlburg HFL, Feinman JA, MacGillivray $\mathrm{MH}$ Aceto $T$. Growth hormone deficiency, brain development, and intelligence. Am $\mathcal{F}$ Dis Child 1978; 132: 565-72.

13 Kusalic M, Fortin C. Growth hormone treatment in hypopituitary dwarfs. Canadian Psychiatric Association fournal 1975; 20: 325-31.

14 Rotnem D, Cohen DJ, Hintz RL, Genel M. Psychological sequelae of relative 'treatment failure' for children receiving human growth hormone replacement. fournal of the American Academy of Child Psychiatry 1979; 19: 505-20.

15 Money J, Pollitt E. Studies in the psychology of dwarfism, II: personality maturation and response to growth hormone
treatment in hypopituitary dwarfs. $\mathcal{F}$ Pediatr 1966 ; 68: 38190.

16 Boulton TJC, Dunn SM, Quigley CA, Taylor JJ, Thompson L. Perceptions of self and short stature: effects of two years of growth hormone treatment. Acta Paediatr Scand 1991; 377: 20-7.

17 Elliot CD, Murray DJ, Pearson LS. British ability scales. Windsor: NFER Nelson, 1983.

18 Rutter M, Tizard J, Whitmore K, eds. Education, health and behaviour. London: Longmans, 1970.

19 Battle J. Culture free self-esteem inventories for children and adults. In: Preston JB, editor and publisher. Seattle, WA Special Child Publications, 1981.

20 Nowicki S, Strickland BR. A locus of control scale for children. $\mathcal{f}$ Consult Clin Psychol 1973; 42: 148-55.

21 Dowdney L, Woodward L, Pickles A, Skuse D. The body image perception and attitude scale for children: reliability in growth retarded and community comparison subjects. International fournal of Methods in Psychiatric Research International four $29-40$.

22 Harter S. Manual of the self-perception profile for children. Denver: University of Denver, 1985.

23 Mitchell CM, Johanson AJ, Joyce S, et al. Psychosocial impact of long-term growth hormone therapy. In: Stable B, Underwood LE, eds. Slow grows the child. New Jersey: Lawrence Erlbaum Associates, 1986:97-109. 